\title{
Influence of Imidazole Carboxylic Acid-Nickel Complex on the Nacre Color in Pearl Oyster
}

\author{
Li-Li Ji ${ }^{1}$, Lu Cai ${ }^{2}$, Jian Guo ${ }^{3}$, Wen-Dong Song ${ }^{4^{*}}$ \\ ${ }^{1}$ Innovation Application Institute, Zhejiang Ocean University, Zhoushan, China \\ ${ }^{2}$ College of Environmental and Science Technology, Donghua University, Shanghai, China \\ ${ }^{3}$ College of Food and Medical, Zhejiang Ocean University, Zhoushan, China \\ ${ }^{4}$ College of Petrochemical and Energy Engineering, Zhejiang Ocean University, Zhoushan, China \\ 1email: jll-gb@163.com \\ 2email: 825902593@qq.com \\ 3email: 626292770@qq.com \\ ${ }^{4}$ email: swd60@163.com.
}

Keywords: 2-ethyl-4, 5-imidazole dicarboxylic acid-nickel complex, pearl oyster, nacre color, microstructure

Abstract. We synthesized an imidazole carboxylic acid-nickel complex, characterized its structure, and transmitted it to P. martensii via dietary algal supplementation. Nacre color was characterized using colorimetry, and its microstructure was observed with scanning electron microscopy (SEM) and atomic force microscopy (AFM). The results show that the nacre formed exhibited a blue shift from yellow in the control group to yellow-green in the nickel complex group. The nickel complex could modify and optimize the nacre. This study provides a theoretical basis of how the acid-metal complex influences P. martensii nacre.

\section{Introduction}

Pearl quality is determined using the following five characteristics: size, shape, color, luster, and surface. Of these, color is a relatively subjective indicator[1]. For instance, black and golden yellow South Sea pearls hold greater value compared to white pearls with similar characteristics. Thus, pearl color has received increasing attention from researchers in recent years [2,3].

In artificial culture, pearls are produced in a process that lasts approximately 20 months [4]. Artificial pearls represent a highly valued export industry. Only 5\% of all harvested pearls can be classified as grade A [5]. Therefore, it is highly desirable from an economic standpoint to improve the quality of cultured pearls.

Imidazole is a five-membered heterocyclic compound containing two nitrogen atoms. As an integral structural component of histidine and purine in DNA and RNA, imidazole is involved in a variety of biochemical processes, plays an important role in physiological activities in vivo, and has a reputation of a "life ligand" [6]. Metal-imidazole complexes have been extensively studied for their interesting structures and potential physiological and biochemical functions [7-9]. In our study, we synthesized an imidazole carboxylic acid-nickel complex, and explored its affection on nacre color in pearl oyster. Our findings provide a scientific foundation for the cultivation of high-quality colored pearls.

\section{Materials and methods}

Nickel complex synthesis. To prepare the metal complex, $1.0 \mathrm{mmol}$ nickel nitrate and $1.0 \mathrm{mmol}$ 2-ethyl-4,5-imidazole dicarboxylic acid were mixed and stirred for $30 \mathrm{~min}$ in air. The $\mathrm{pH}$ of the mixture was adjusted to 6.5 using $\mathrm{NaOH}$, after which it was placed in a Teflon reactor, heated to $433 \mathrm{~K}$ 
for 4 days, and cooled to room temperature at the rate of $10 \mathrm{~K} \cdot \mathrm{h}^{-1}$. The resultant crystals were washed with water and dried in air.

X-ray single-crystal diffraction. A suitable single crystal was selected from the nickel complex, mounted on a Rigaku Mercury-CCD diffractometer (Rigaku Corporation, Japan) equipped with a graphite monochromatic Mo-K $\alpha$ radiation $(\lambda=0.71073 \AA)$ at $298 \mathrm{~K}$. All absorption corrections were performed using the Crystal Clear program. Structures were solved by the direct method and refined by full-matrix least-squares fitting on F2 using the SHELXTL-97 program package. All non-hydrogen atoms were refined with anisotropic displacement parameters. Hydrogen atoms were located at geometrically calculated positions.

Color characterization. Nacre color was characterized using a CIE standard colorimetric system. Nacre reflectance was analyzed using a spectrometer (WDS-8A, Optical Instrument Factory, Tianjin, China), and a chromaticity diagram was used to calculate the chromaticity coordinates and to characterize the color.

Microstructure characterization. The nacre was extracted from the shell by mechanical crushing, and the cross-section of the nacre was visualized using scanning electron microscopy (SEM, S-4800, Hitachi Corporation, Japan) and atomic force microscopy (AFM, SPA-300HV, Seiko Corporation, Japan) to analyze its microstructure.

\section{Results and discussion}

Structure of the nickel complex. The results of the single-crystal X-ray diffraction studies revealed that the compound crystallizes in the triclinic space group $\mathrm{P}^{\overline{1}}$. Fig. 1 shows the thermal ellipsoid plot, and Tables 1 and 2 present the crystallographic data, bond lengths, and bond angles of the nickel complex. The asymmetric unit consists of one $\mathrm{Ni}$ (II) cation, one 2-ethyl-4,5-imidazole dicarboxylic acid ligand molecule, a combined $\mathrm{H}_{2} \mathrm{O}$ and a semi-free $\mathrm{H}_{2} \mathrm{O}$. The $\mathrm{Ni}(\mathrm{II})$ ion is six-coordinated by two oxygen atoms and nitrogen atoms from two different ligands, and two combined $\mathrm{H}_{2} \mathrm{O}$, forming an octahedral structure.

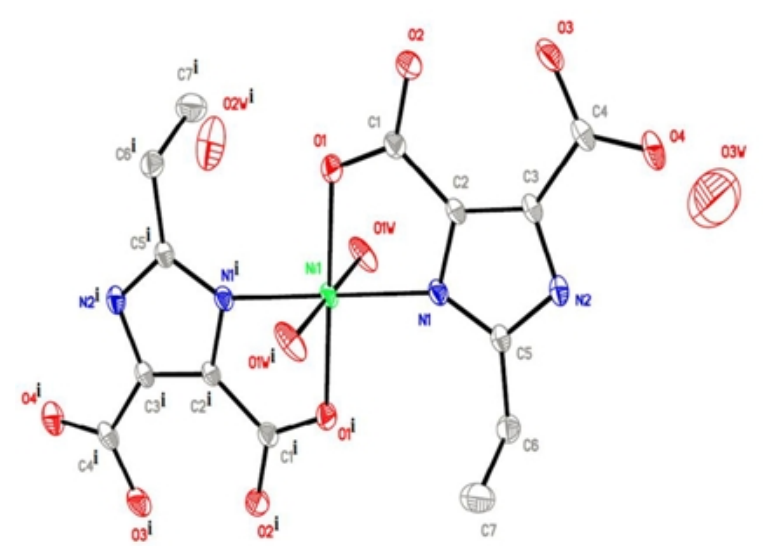

Fig. 1 The molecular structure of nickel complex. Thermal ellipsoid plot showing the molecular structure of the synthesized nickel complex. 
Table 1. Crystallographic data and structure refinement of the nickel complex

\begin{tabular}{|c|c|c|c|}
\hline Empirical formula & $\begin{array}{c}{\left[\mathrm{Ni}\left(\mathrm{C}_{7} \mathrm{H}_{7} \mathrm{~N}_{2} \mathrm{O}_{4}\right)_{2}\left(\mathrm{H}_{2} \mathrm{O}\right)_{2}\right] \bullet} \\
3 \mathrm{H}_{2} \mathrm{O}\end{array}$ & $F(000)$ & 268 \\
\hline Formula weight & 515.08 & $D_{\text {calc }}\left[\mathrm{mg} / \mathrm{cm}^{3}\right]$ & 1.687 \\
\hline Crystal system & Triclinic & $\begin{array}{c}\text { Absorption coefficient } \\
{\left[\mathrm{mm}^{-1}\right]}\end{array}$ & 1.035 \\
\hline Space group & $\mathrm{P}_{\overline{1}}$ & GOF & 1.651 \\
\hline$a[\AA]$ & $7.1972(6)$ & Crystal size [mm] & $0.40 \times 0.30 \times 0.25$ \\
\hline$b[\AA ̊]$ & $8.8436(7)$ & $\begin{array}{c}\theta \text { range for data collection } \\
{\left[{ }^{\circ}\right]}\end{array}$ & $2.41-27.50$ \\
\hline$c[\AA]]$ & $9.3187(7)$ & Limiting indices & $\begin{array}{c}-9 \leq \mathrm{h} \leq 9 \\
-11 \leq \mathrm{k} \leq 11 \\
-12 \leq 1 \leq 12\end{array}$ \\
\hline$\alpha\left[^{\circ}\right]$ & $66.2410(10)$ & $\begin{array}{c}\text { Reflections } \\
\text { collected/unique }\end{array}$ & $4907 / 2330$ \\
\hline $\boldsymbol{\beta}\left[^{\circ}\right]$ & $89.0610(10)$ & Completeness to $\theta=25.00$ & $99.70 \%$ \\
\hline$\gamma\left[^{\circ}\right]$ & $70.5500(10)$ & $\begin{array}{c}\text { Data/restraints/ } \\
\text { parameters }\end{array}$ & $2330 / 16 / 159$ \\
\hline$V\left[\AA^{3}\right]$ & $507.09(7)$ & Final $R$ indices $[\mathrm{I}>\mathbf{2} \sigma(I)]$ & $\begin{array}{c}\mathrm{R} 1=0.0490, w \mathrm{R} 2= \\
0.1472\end{array}$ \\
\hline$Z$ & 1 & $R$ indices (all data) & $\begin{array}{c}\mathrm{R} 1=0.0501, \mathrm{wR} 2= \\
0.1480\end{array}$ \\
\hline
\end{tabular}

Table 2. Bond lengths and angles of the nickel complex

\begin{tabular}{|c|c|c|c|}
\hline Bond length & [̊̊] & Bond angle & {$\left[{ }^{\circ}\right]$} \\
\hline Ni1(1)-O(1W) & $2.06(11)$ & $\mathrm{O}(1 \mathrm{~W})-\mathrm{Ni} 1(1)-\mathrm{O}(1 \mathrm{~W}) \# 1$ & $180(2)$ \\
\hline $\mathrm{Ni1}(1)-\mathrm{O}(1 \mathrm{~W}) \# 1$ & $2.06(11)$ & $\mathrm{O}(1 \mathrm{~W})-\mathrm{Ni1}(1)-\mathrm{N}(1) \# 1$ & $89(5)$ \\
\hline Ni1(1)-N(1)\#1 & $2.07(11)$ & $\mathrm{O}(1 \mathrm{~W}) \# 1-\mathrm{Ni1}(1)-\mathrm{N}(1) \# 1$ & $91(5)$ \\
\hline Ni1(1)-N(1) & $2.07(11)$ & $\mathrm{O}(1 \mathrm{~W})-\mathrm{Ni1}(1)-\mathrm{N}(1)$ & $91(5)$ \\
\hline Ni1(1)-O(1) & $2.10(11)$ & $\mathrm{O}(1 \mathrm{~W}) \# 1-\mathrm{Ni1}(1)-\mathrm{N}(1)$ & $89(5)$ \\
\hline \multirow[t]{10}{*}{ Ni1(1)-O(1)\#1 } & $2.10(11)$ & N(1)\#1-Ni1(1)-N(1) & $179.998(16)$ \\
\hline & & $\mathrm{O}(1 \mathrm{~W})-\mathrm{Ni1}(1)-\mathrm{O}(1)$ & $88(5)$ \\
\hline & & $\mathrm{O}(1 \mathrm{~W}) \# 1-\mathrm{Ni1}(1)-\mathrm{O}(1)$ & $92(5)$ \\
\hline & & N(1)i1-N\#1(1)-O(1) & $100(4)$ \\
\hline & & $\mathrm{N}(1)-\mathrm{Ni1}(1)-\mathrm{O}(1)$ & $80(4)$ \\
\hline & & $\mathrm{O}(1 \mathrm{~W})-\mathrm{Ni1}(1)-\mathrm{O}(1) \# 1$ & $92(5)$ \\
\hline & & $\mathrm{O}(1 \mathrm{~W}) \# 1-\mathrm{Ni1}(1)-\mathrm{O}(1) \# 1$ & $88(5)$ \\
\hline & & N(1)\#1-Ni1(1)-O(1)\#1 & $80(4)$ \\
\hline & & N(1)-Ni1(1)-O(1)\#1 & $100(4)$ \\
\hline & & $\mathrm{O}(1)-\mathrm{Ni1}(1)-\mathrm{O}(1) \# 1$ & $179.999(12)$ \\
\hline
\end{tabular}

Color characterization. The nacre color obtained after the oysters were fed algae containing the nickel complex, compared to the control group, is illustrated in Fig. 2. The nickel complex group shows a yellow-green nacre, while the nacre of the control group can be seen as faint yellow. 


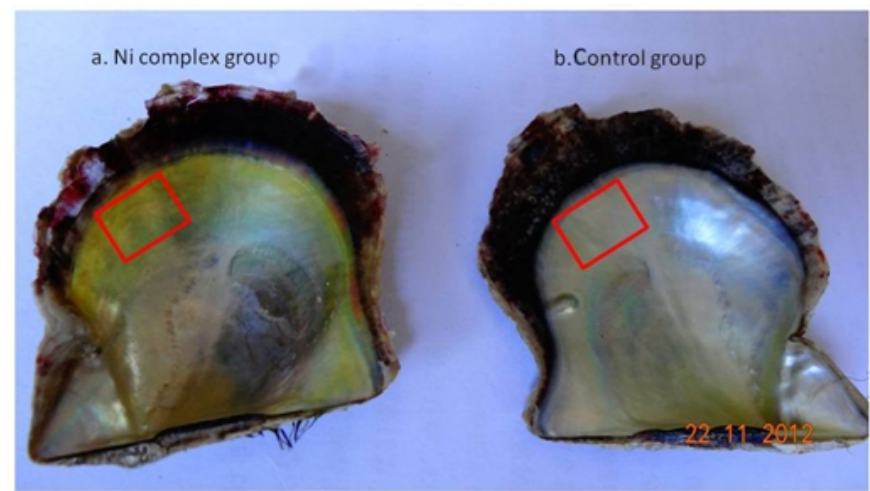

Fig. 2 Images of the nacre color. (a) is nickel complex treated and (b) is control oysters. The red box indicates the sampling location. Scale bars =1:1.6.

As shown in Fig. 3, when light is incident vertically on the surface of nacre, the reflection spectra of the nickel complex and control groups were 475-650nm and 500-640nm, respectively. The reflection spectrum of nacre in the nickel complex group exhibited a blue shift compared to the control group.

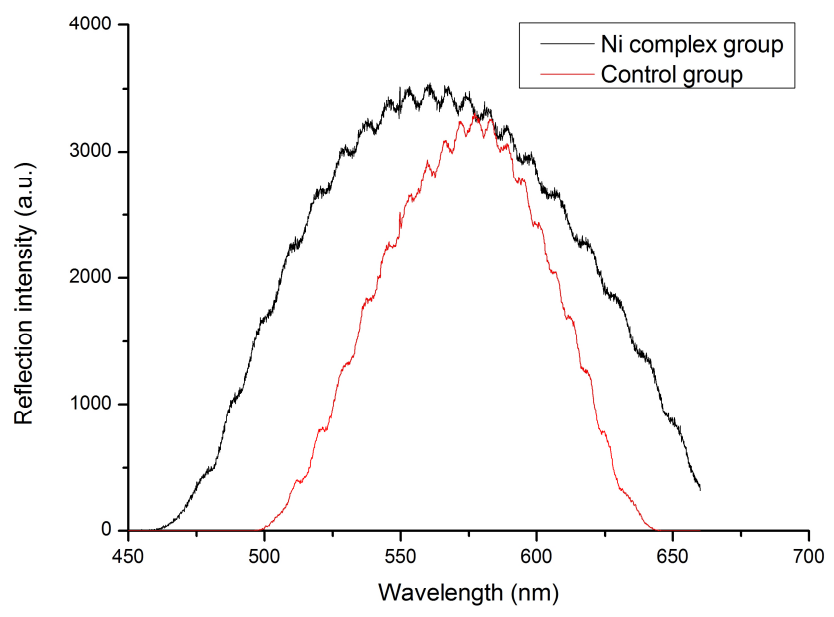

Fig. 3 Spectral reflectance curves of the nacre. Spectral reflectance curves of the nacre of nickel complex-treated and control oysters at normal vertical incidence. A blue shift is observed in the nickel complex treated group compared to the control.

Fig.4 shows the CIE chromaticity diagram of nacre. As shown in the figure, the chromaticity coordinates of the control and nickel complex groups were $(0.4661,0.5272)$ and $(0.4245,0.5323)$, the dominant wavelengths were 577 and $560 \mathrm{~nm}$, and the dominant tones were yellow and yellow-green and consistent with visual color, respectively (shown in Fig. 2). Nacre is known to contain over $95 \%$ calcium carbonate, while metal and organic matter account for the remaining 5\%. In our study, the nickel complex transmitted to $P$. martensii via dietary algae resulted in a yellow-green color to the nacre, possibly by altering the nacre microstructure, producing structural color. Therefore, further studies are required to observe the influence of the nickel complex on the structure of nacre. 


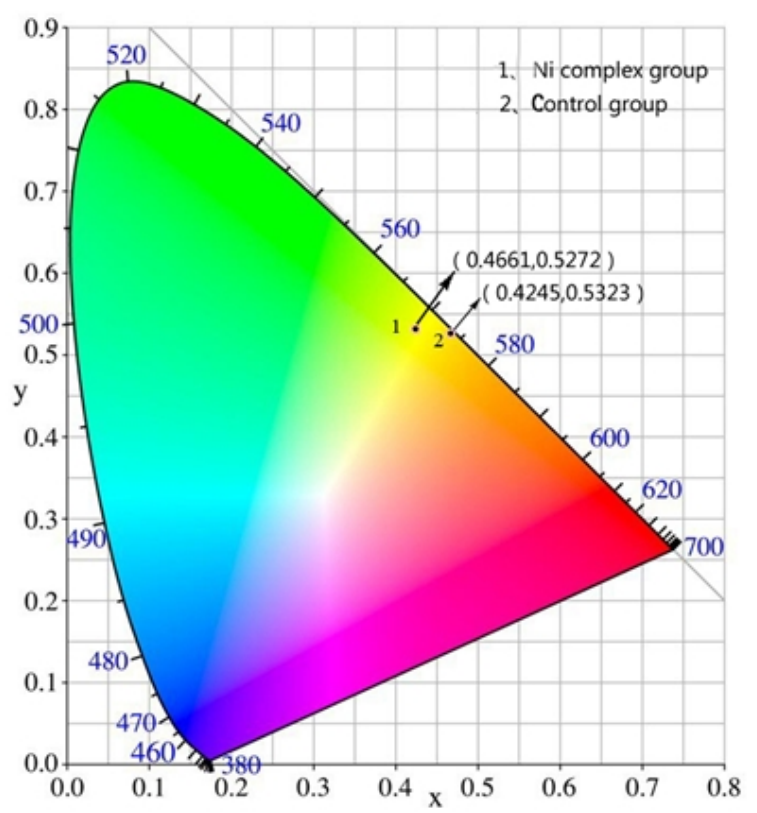

Fig. 4 CIE chromaticity diagram. CIE chromaticity diagram displaying the coordinates of nickel complex treated and control oyster nacre.

Microstructure characterization. SEM images of the nacre microstructure revealed that the layered structure of the nacre surface in the control group had indistinct layering, unevenly arranged aragonites, and particle fragments (Fig. 5). In the nickel complex-treated group, SEM of the nacre revealed clear overlaps and obvious regular hexagonally shaped aragonites in every layer. Further analysis by AFM was carried out, and the three-dimensional images are shown in Fig. 6. The control group nacre had a considerably rough and rugged surface, while the nacre in the nickel complex-treated group has a smooth surface. These results verify that the nickel complex indeed has an impact on the microstructure of nacre, and could be used to modify and optimize the nacre for an improved quality.

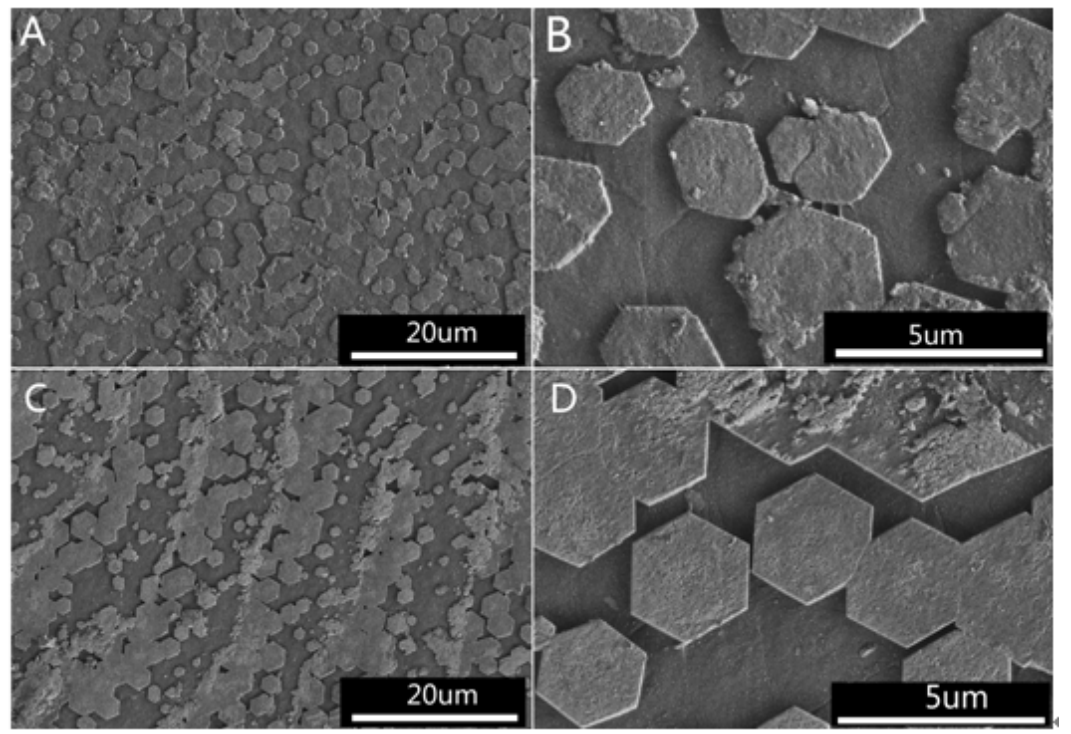

Fig. 5 SEM images of the microstructure. Representative SEM images of the microstructure of (A, B) control nacre and (C, D) nickel complex-treated nacre, at (A, C) 2000× and (B, D) $10000 \times$ magnification. The nickel complex-treated group shows clear layer overlaps and regular hexagonally shaped aragonites. Scale bars $(\mathrm{A}, \mathrm{C})=$ $1: 750$ and scale bars $(\mathrm{B}, \mathrm{D})=1: 4000$. 

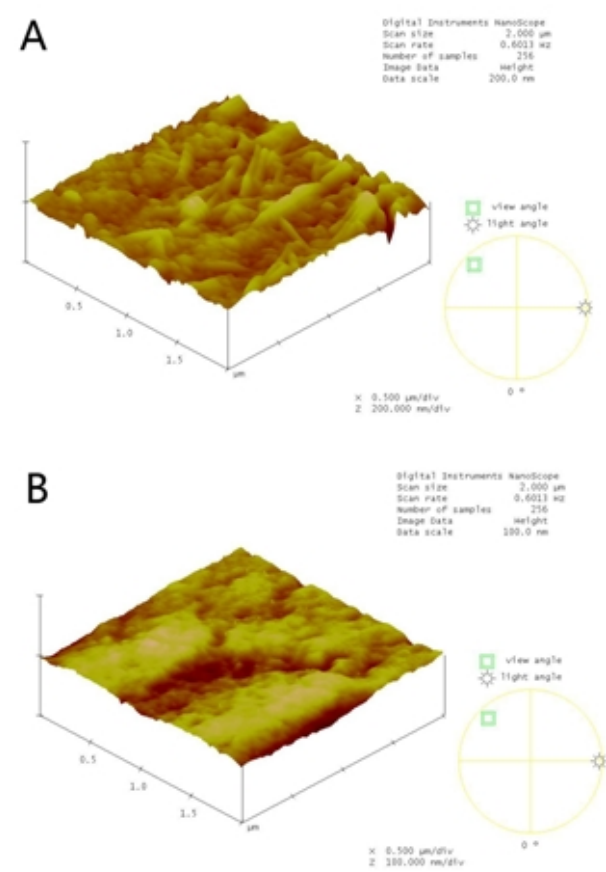

Fig. 6 Atomic force microscopy images of nacre. Atomic force microscopy images of nacre in the (A) control group showing a rough surface and in the (B) nickel complex treated group showing a smooth surface.

Currently, there is no globally accepted system to grade the value of pearls [10]. However, for commercial purposes, pearls are categorized into grades $\mathrm{A}-\mathrm{C}$ [5] based on subjective characteristics such as color and luster and measurable characteristics such as nacre thickness, size, and shape. Based on our findings, we believe that the imidazole carboxylic acid-nickel complex positively influenced all these attributes and would therefore improve the grade of the pearls, consequently increasing its commercial value. Further investigations should focus on the precise mechanism by which the metal-acid complex influences the quality and properties of nacre.

\section{Conclusion}

Imidazolecarboxylic acid-nickel complex is considered an artificial inducer which, when transmitted to $P$. martensii through dietary algae, was found in the present study to alter its nacre color from yellow to yellow-green. Therefore, the imidazole carboxylic acid-nickel complex might participate in the nacre structure, affect nacre secretion, as well as alter the nacre color toward the shorter wavelength. Taken together, our results not only provide an innovative approach for the cultivation of colorful pearls by artificial regulation but also provide insights into the effect of imidazole carboxylic acid-nickel complex on nacre.

\section{Acknowledgements}

This study was supported by the Natural Science Foundation of Zhejiang Province, China (No. LQ16D060004), the Science and Technology Plan Project of Zhoushan (No. 2015C41013), and the Research Startup Foundation of Zhejiang Ocean University.

\section{References}

[1] E.L. McGinty, B.S. Evans, J.U.U. Taylor and D.R Jery: Aquaculture Vol. 302 (2010), p. 175-181.

[2] C. Hedegaard, J.O. Bardeau and D. Chateigner: J. Mollus. Stud. Vol. 72 (2006), p. 157-162.

[3] M.R. Snow, A. Pring, P. Self and J.G. Shapter: Am. Min. Vol. 89 (2004), p. 1353-1358. 
[4] J.J.U. Taylor and E. Strack, in: The pearl oyster, edited by P.C. Southgate \& J.S. Lucas, Elsevier publishing, Amsterdam, Netherlands (2008)

[5] S. Ellis and M. Haws. Waimanalo, Hawaii, Center for Tropical and Subtropical Aquaculture Press (1999), Report No. 141.

[6] J.R. Lewis: Nat.Prod.Rep. Vol. 19(2002), p. 223.

[7] C.J. Li, S. Hu and W. Li: Euro. J. Inorg. Chem. Vol. 10(2006), p. 1931-1935.

[8]T.K. Maji, G. Mostafa, H. Chang and S. Kitagawa: Chem. Comm. Vol. 19(2005), p. 2436.

[9] Y.Q. Sun and G.Y. Yang: J. Am. Chem. Soc. Vol. 251 (2007), p. 3771-3781.

[10]Y. Ota, H. Higashi and S. Nakauchi. InAdvanced Informatics: Concepts, Theory and Applications (ICAICTA), Chonburi, Thailand, IEEE Press(2015). 